\title{
PENGARUH HARAPAN PELANGGAN DAN KUALITAS PELAYANAN TERHADAP KEPUASAN PELANGGAN PADA PDAM KABUPATEN BULELENG
}

\author{
K.A. Subawa ${ }^{1}$, N.L.W.S Telagawathi ${ }^{2}$ \\ 1,2Jurusan Manajemen, Universitas Pendidikan Ganesha, Singaraja \\ e-mail: arta.subawa@undiksha.ac.id, wayan.sayang@undiksha.ac.id
}

\begin{abstract}
Abstrak
Penelitian ini memiliki tujuan untuk menguji pengaruh harapan pelanggan dan kualitas pelayanan terhadap kepuasan pelanggan pada PDAM Kabupaten Buleleng baik secara parsial ataupun simultan. Metode penelitian ini adalah kuantitatif kausal. Dalam penelitian ini pelanggan PDAM Kabupaten Buleleng sebagai subjek dan objeknya adalah harapan pelanggan, kualitas pelayanan, serta kepuasan pelanggan. Sampel berjumlah 80 orang. Data berasal dari kuesioner kemudian dianalisis menggunakan analisis regresi linier berganda. Hasil menunjukkan bahwa (1) adanya pengaruh signifikan antara harapan pelanggan dan kualitas pelayanan terhadap kepuasan pelanggan, (2) antara harapan pelanggan terhadap kepuasan berpengaruh positif dan signifikan,serta (3) antara kualitas pelayanan terhadap kepuasan berpengaruh positif dan signifikan.
\end{abstract}

Kata kunci: kualitas pelayanan, harapan pelanggan, kepuasan pelanggan.

\begin{abstract}
This research aimed to examine the customer effect expectations and service quality of customer satisfaction at PDAM Buleleng Regency both partial and simultan. The research design used a quantitative causal. PDAM Buleleng Regency customers as subject and the customer expectation, service quality, customer satisfaction as object,. The sample amounted 80 people. The data from questionnaire and then analyzed used multiple linear regression analysis. The results showed: (1) there are significant effect between customer expectations to customer satisfaction, (2) between service expectations to customer satisfaction had a positive and significant effect, (3) between service quality to customer satisfaction had a significant effect.
\end{abstract}

Keywords: customer expectations, customer satisfaction, service quality.

\section{Pendahuluan}

Air merupakan hal terpenting dalam kehidupan manusia, karena tanpa air manusia tidak dapat hidup, oleh karena itu kebutuhan air menjadi kebutuhan terpenting yang harus diutamakan. Penyediaan akan air bersih yang sehat selalu menjadi tuntutan, tidak terkecuali bagi masyarakat Indonesia. Perusahaan Daerah Air Minum (PADM) menurut UU No 5 tahun 1962 adalah suatu kesatuan usaha milik pemerintah daerah yang bertugas memberikan jasa pelayanan dan menyelenggarakan kemanfaatan umum dibidang air minum.

Di Indonesia pendistribusian air dijalankan PDAM. PDAM diharapkan setiap waktu dapat meningkatkan pelayanannya dalam memenuhi kepuasan pelaanggannya. Seiring pesatnya pertumbuhan angka kelahiran yang berpengaruh terhadap peningkatan jumlah penduduk di Provinsi Bali khususnya di Kabupaten Buleleng berbanding lurus dengan kebutuhan air bersih. PDAM Kabupaten Buleleng hadir di Kabupaten Buleleng untuk melayani pendistribusian air. Adapun cabang dan unit yang dibawah operasional PDAM Kabupaten Buleleng meliputi Cabang Singaraja, Cabang Seririt, Cabang Gerokgak, Cabang Busungbiu, Unit Pancasari, Cabang Kubutambahan, Unit Sambirenteng, Cabang Lovina dan Unit Pejarakan.

Adapun jenis pelayanan yang diberikan oleh PDAM Kabupaten Buleleng kepada masyarakat yaitu: proses sambungan baru, proses permohonan pindah meteran air, permohonan balik nama rekening, mengentri data stan meter air pelanggan, menerima laporan pelanggan secara langsung, menerima laporan pelanggan melalui telepon, pengumuman perbaikan kebocoran lewat radio, pembacaan stan meter air pelanggan. Berdasarkan data 
yang didapat dari PDAM Kabupaten Buleleng diketahui angka penduduk dan jumlah sambungan untuk tahun 2016 sejumlah 46.015. PDAM Kabupaten Buleleng sudah mampu memenuhi kebutuhan air untuk penduduk di luar Kota Singaraja seperti, untuk daerah Pejarakan, Grokgak, Busungbiu, Pancasari, Sambirenteng, Kubutambahan, Seririt dan Lovina. Pelayanan terbanyak pada wilayah Cabang Singaraja mencapai 25232 pelanggan.

Zeithaml et. al. (dalam Tjiptono dan Chandra, 2011) mengungkap bahwa, kualitas pelayanan merupakan tingkat keunggulan untuk memenuhi harapan konsumen. Kualitas pelayanan dibentuk oleh perbandingan antara ideal dan persepsi kinerja kualitas; kualitas pelayanan dapat dilihat dari kepercayaan konsumen terhadap janji perusahaan (Oliver, 1993). Secara spesifik, pentingnya meningkatkan kualitas pelayanan adalah untuk mendapatkan kepuasan pelanggan dengan menjadikan pelanggan sebagai fokus utamanya. Persoalan kualitas jasa dan kepuasan pelanggan kini semakin menjadi hal penting dan urgent bagi perusahaan jasa. Perusahaan perlu membentuk sistem manajemen kualitas jasa, mengidentifikasi kesenjangan yang mungkin terjadi, serta pengaruhnya bagi kepuasan konsumen dan perilaku konsumen purna pelayanannya (Setyani, 2011).

Pelayanan PDAM Kabupaten Buleleng memiliki lima dimensi kualitas pelayanan yakni dari reliability, assurance, tangibles, emphaty, dan responsiveness. Dimensi inilah yang sering digunakan oleh perusahaan untuk meningkatkan mutu pelayanan pelanggan. PDAM Kabupaten Buleleng juga menggunakan dimensi ini dalam menilai tingkat pelayanan. Tingkat kualitas pelayanan tidak hanya dapat diukur dari sudut pandang penilaian lembaga namun harus diukur dari sudut pandang pelanggan. Kualitas pelayanan yang diberikan oleh PDAM Buleleng masih jauh dari harapan pelanggan, ini dapat dipandang dari keluhan masyarakat yang tertuju kepada PDAM Buleleng. Masalah-masalah yang dihadapi oleh PDAM mengenai pelayanannya antara lain: tingkat kebocoran relatif tinggi terutama pada jam-jam puncak pemakaian air, Penanganan kebocoran agak lambat karena masih menggunakan system manual, prosentase pelayanan relatif masih kecil terutama di daerah-daerah pedesaan, karena sistem jaringan distribusi kurang memadai, pada daerah pelayanan tertentu dengan sistem perpompaan dengan daya PLN sering mengalami hambatan pelayanan pada waktu PLN mati sehingga pompa tidak operasional, dan PDAM lebih berorientasi pada profit sehingga fungsi pelayanan atau sosial dikurangi.

Untuk menggali tanggapan pelanggan terhadap kualitas pelayanan dan harapan pelanggan yang telah dilakukan, pihak manajemen PDAM Kabupaten Buleleng telah melakukan survei pada tahun 2016. Survei yang dilakukan dengan menggali tanggapan pelanggan mengenai dimensi kualitas pelayanan seperti: image/ pandangan terhadap keberadaan PDAM Kabupaten Buleleng, prosedur pelayanan, kejelasan dan kepastian pelayanan, profesionalisme petugas, kecepatan penanganan gangguan, keamanan dan kenyamanan di lingkungan pelayanan PDAM Kabupaten Buleleng, kontinyuitas aliran air, kualitas air, rutinitas pembacaan stan meter, dan tarif air. Adapun hasil dari survei diketahui bahwa ada penurunan kualitas pelayanan terutama selama bulan Desember dimana berdasarkan data awal survei di bulan Januari total prosentase pelayanan langganan mencapai $83,47 \%$ dan menurun tajam pada bulan Desember dimana prosentase terlayani hanya $45,49 \%$ saja. Berdasarkan data survei yang dilakukan pada tanggal 10 Januari 2017 yang dibuat oleh Putu Netry Indriani sebagai Ka. Sub. Bag. Pelanggan dari PDAM Kabupaten Buleleng, terbukti bahwa ada penurunan prosentase pelayanan langganan pada Wilayah/ Cabang Kabupaten Buleleng yang juga menunjukkan bahwa pelayanan PDAM Kabupaten Buleleng belum memenuhi apa yang diharapkan oleh pelanggan.

Harapan dibagi menjadi dua yaitu kemungkinan dan evaluasi dari yang terjadi (Oliver, 1993). Harapan dipengaruhi oleh pengalaman pelanggan, pernyataan atau infomasi dari sumber perusahaan seperti misalnya dari iklan, media dan teman, juga dari informasi pesaing dan janji perusahaan (Widodo, 2009). Variabel harapan pelanggan diyakini mempunyai peranan yang besar dalam menentukan kualitas produk (barang atau jasa) dan kepuasan pelanggan. Dalam mempertimbangkan pilihannya, pelanggan akan menggunakan harapannya sebagai standar atau acuan pelanggan dalam memilih suatu produk, baik barang maupun jasa (Pratiwi, 2010). 
Layanan berkualitas dan sesuai harapan pelanggan berperan penting dalam membentuk kepuasan pelanggan, selain itu juga berkaitan langsung untuk mendapatkan keuntungan bagi perusahaan. Kotler (2005) menyatakan kepuasan pelanggan adalah perasaan senang atau kecewa dari orang yang muncul setelah membandingkan antara persepsi atau kesannya terhadap hasil kerja suatu produk dan segala harapannya, sedangkan Wilkie (1990) mengartikan kepuasan pelanggan sebagai suatu tanggapan emosial pada pengukuran atau evaluasi terhadap pengalaman konsumsi suatu produk atau jasa. Oleh karena itu dapat diartikan bahwa kepuasan konsumen merupakan perbedaan antara nilai harapan dengan situasi perusahaan didalam usaha memenuhi harapan konsumen. Pemenuhan harapan akan didapatkan kepuasan bagi konsumen.

Untuk melihat bagaimana kondisi sebenarnya mengenai harapan pelanggan, kualitas pelayanan dan kepuasan pelanggan PDAM Kabupaten Buleleng, pada tanggal 12 Februari 2019 dilakukan observasi awal oleh peneliti di PDAM Kabupaten Buleleng di Jalan Melati No.17 Singaraja. Lokasi ini dipilih karena merupakan subjek penelitian di dalam research ini. Pra-survey dilakukan dengan penyebaran angket sementara yang terdiri dari indikator mengenai harapan pelanggan, kualitas pelayanan dan kepuasan pelanggan kepada 10 pelanggan. Kondisi kepuasan pelanggan PDAM Kabupaten Buleleng secara keseluruhan belum sesuai dengan yang diharapkan. Hasil skor yang diperoleh dari jawaban sementara responden pada kuesioner awal menunjukan angka 80 dengan rentang kategori 50 -100 maka dapat dikatakan bahwa harapan pelanggan pada PDAM Kabupaten Buleleng berada pada kategori rendah. Berdasarkan data tersebut dapat dilihat bahwa pelanggan merasa pernyataan layanan PDAM Kabupaten Buleleng belum sesuai harapan dan belum ada perubahan pelayanan yang berarti. Contohnya di beberapa daerah, PDAM sering membuat pengumuman pendistribusian air bergilir dan menghimbau masyarakat untuk menampung air karena proses tersebut. Hal tersebut disebabkan karena di beberapa titik masih merupakan jaringan tua sehingga distribusi air kerap tersendat karena pipa bocor. Tentu keadaan ini tidak sesuai dengan harapan pelanggan dan tidak memuaskan pelanggan yang menginginkan kebutuhan akan air bersih dapat dinikmati setiap hari.

Kondisi kepuasan pelanggan PDAM Kabupaten Buleleng secara keseluruhan belum sesuai dengan yang diharapkan. Hasil skor yang diperoleh dari jawaban sementara responden pada kuesioner awal menunjukan angka 80 yang berada pada rentang kategori 50-100 maka dapat dikatakan bahwa harapan pelanggan pada PDAM Kabupaten Buleleng berada pada kategori rendah. Berdasarkan data tersebut dapat dilihat bahwa pelanggan merasa pernyataan layanan PDAM Kabupaten Buleleng belum sesuai harapan dan belum ada perubahan pelayanan yang berarti. Contohnya di beberapa daerah, PDAM sering membuat pengumuman pendistribusian air bergilir dan menghimbau masyarakat untuk menampung air karena proses tersebut. Hal ini disebabkan karena di beberapa titik masih merupakan jaringan tua sehingga distribusi air kerap tersendat karena pipa bocor. Tentu keadaan ini tidak sesuai dengan harapan pelanggan dan tidak memuaskan pelanggan yang menginginkan kebutuhan akan air bersih dapat dinikmati setiap hari. Jika pelanggan tidak puas, hal ini dapat dilihat dari hasil skor yang diperoleh dari jawaban sementara responden pada kuesioner awal menunjukan angka 59 yang berada pada rentang kategori 50-100 maka dapat dikatakan bahwa harapan pelanggan pada PDAM Kabupaten Buleleng berada pada kategori rendah. Ketidakpuasaan ini terindikasi terjadi akibat terpengaruh oleh harapan dan kualitas pelayanan. Pelanggan merasa layanan yang ditawarkan tidak sesuai harapan dan kualitas pelayanan yang dirasakan pelanggan selama menggunakan jasa PDAM kabupaten Buleleng kurang baik.

Semakin berkualitas layanan yang diberikan oleh perusahaan dan sesuai harapan maka kepuasan yang dirasakan oleh konsumen akan semakin meningkat. Dari hal tersebut di atas, bahwa adanya pengaruh antara harapan, kualitas pelayanan terhadap kepuasan pelanggan. Hal ini selaras dengan skripsi Abdullatif tahun 2016 yang menyebutkan bahwa secara simultan dan parsial harapan pelanggan, kualitas pelayanan berpengaruh terhadap kepuasaan pelanggan.

Tolak ukur pelayanan pelanggan berbeda, tergantung pada kepuasan dan harapan terhadap PDAM. Kita tidak mampu menghindari kenyataan bahwa perusahaan harus 
memuaskan pelanggannya untuk mempertahankan loyalitas pelanggan. Kepuasan pelanggan berasal dari hati, yaitu sadar dengan pentingnya seorang pelanggan dan kepuasan pelanggan harus terus terjalin. Atas dasar tersebut, penulis memiliki daya tarik untuk melakukan penelitian pengaruh antara harapan pelanggan dan kualitas pelayanan terhadap kepuasan pelanggan PDAM. Maka penulis melakukan penelitian dengan judul "Pengaruh Harapan Pelanggan dan Kualitas Pelayanan Terhadap Kepuasan Pelanggan pada PDAM Kabupaten Buleleng".

\section{Metode}

Riset ini dilaksanakan pada Fakultas Ekonomi Universitas Pendidikan Ganesha. Rancangan penelitian menggunakan penelitian kuantitatif. Ditetapkan harapan pelanggan dan kualitas pelayanan sebagai variabel independen dan kepuasan pelanggan pada PDAM Kabupaten Buleleng sebagai variabel dependen. Mahasiswa Fakultas Ekonomi Universitas Pendidikan Ganesha adalah subjek. Harapan pelanggan, kualitas pelayanan, dan kepuasan pelanggan pada PDAM Kabupaten Buleleng adalah objek penelitian. Populasi yang digunakan adalah seluruh pelanggan PDAM Kabupaten Buleleng. Dalam menentukan jumlah sampel dalam penelitian ini menggunakan rumus Slovin bahwa populasi relatif homogen sehingga tidak terlalu diperlukan untuk distratifikasi sebagai pertimbangan. Hasil perhitungan dengan rumus Slovin menunjukkan jumlah sampel adalah 80 pelanggan. Dasar penggunaan rumus tersebut adalah untuk didapatkan sampel yang representative dan lebih mendekati populasi.

Sumber data dalam penelitian ini adalah data primer. Yang dimaksud dengan data primer adalah data sumber pertama. Data primer berupa data tentang harapan pelanggan, kualitas pelayanan, dan kepuasan pelanggan pada PDAM Buleleng. Data harapan pelanggan, kualitas pelayanan, dan kepuasan pelanggan pada PDAM Buleleng bersumber dari jawaban angket oleh responden yang dijawab langsung.

Teknik kuesioner digunakan untuk pengumpulan data dalam penelitian ini. Teknik ini dilakukan dengan cara memberikan beberapa pertanyaan kepada responden untuk dijawab yang berhubungan dengan variabel yang akan diteliti, yaitu variabel harapan pelanggan, kualitas pelayanan, dan kepuasan pelanggan pada PDAM Buleleng. Dalam pengukuran variabel menggunakan metode kuesioner, variabel harapan pelanggan, kualitas pelayanan, dan kepuasan pelanggan pada PDAM Buleleng diurai ke dalam beberapa indikator yang menjadi pertanyaan kepada responden dalam penelitian.

Pengolahan data yang dikumpulkan menggunakan sistem penilaian kuesioner skala likert. Skala ini digunakan karena hasil kuesioner merupakan data ordinal, sedangkan analisis regresi linear berganda yang digunakan sebagai pembuktian kebenaran hipotesis dalam mengisyaratkan minimal data interval, maka data ordinal tersebut perlu ditingkatkan skala pengukurannya menjadi skala interval melalui method of successive interval dari Hays (1969).

Desain kausal digunakan dalam penelitian ini untuk mengukur kuat hubungan antar variabel dalam penelitian. Dalam mencari pengaruh dari harapan pelanggan dan kualitas pelayanan terhadap kepuasan pelanggan pada PDAM Buleleng menggunakan analisis regresi linier berganda. Uji asumsi klasik yang terdiri dari uji normalitas, uji multikolinieritas, dan uji heteroskedastisitas maka dilakukan analisis regresi.

\section{Hasil dan Pembahasan}

Hasil uji normalitas data menggunakan One Sample Kolmogorov-Smirnov Test menunjukkan bahwa sebaran data berdistribusi normal. Distribusi normal karena uji normalitas data ditunjukkan nilai signifikansinya sebesar 0,200. Nilai signifikansi tersebut lebih besar dari 0,05 untuk statistik One Sample Kolmogorov-Smirnov. Berdasarkan kriteria uji normalitas, data terdistribusi normal jika nilai signifikansi lebih besar dari 0,05.

Model regresi baik harusnya tidak terjadi korelasi yang tinggi diantara variabel independen. Uji multikoliniearitas bertujuan mengetahui ada atau tidak hubungan antara variabel independen satu dengan variabel yang lainnya. Uji multikolinieritas menggunakan Variance Inflation Factor (VIF) dan toleransi. Jika nilai VIF kurang dari 10 atau toleransi lebih dari 0,10 , maka dinyatakan tidak terjadi gejala multikolinearitas. Berdasarkan hasil uji multikolinieritas diketahui bahwa nilai VIF dari masing-masing variabel harapan pelanggan dan 
kualitas pelayanan sebesar 1,679 lebih kecil dari 10 dan nilai toleransi sebesar 0,596 lebih dari 0,10 . Nilai korelasi diantara variabel harapan pelanggan dan kualitas pelayanan dapat dikatakan mempunyai korelasi yang lemah. Dengan demikian dapat disimpulkan bahwa diantara variabel independen tidak terjadi gejala multikolinearitas.

Model regresi yang baik dan diharapkan adalah model yang tidak terjadi heteroskedastisitas. Uji heteroskedastisitas memiliki tujuan untuk menguji apakah dalam model regresi terjadi ketidaksamaan varian dari residual satu pengamatan ke pengamatan yang lainnya. Grafik scatterplot di gunakan untuk menguji heteroskedastisitas. Hasil uji heteroskedastisitas dapat dibaca melalui grafik scatterplot pada Gambar 1.

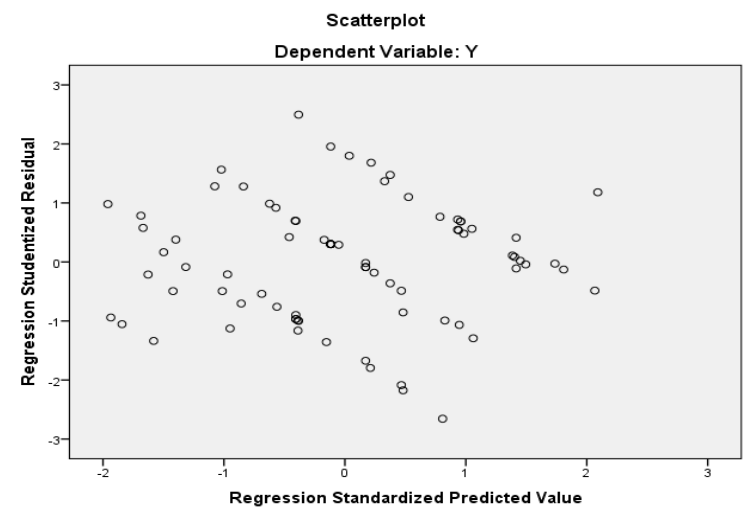

Gambar 1

Grafik Scatterplot

(Sumber: Data Diolah, 2019)

Pada Gambar 1 ditunjukkan bahwa sebaran titik yang ditimbulkan terbentuk secara acak, tidak berpola tertentu serta arah penyebarannya berada diatas ataupun dibawah angka 0 pada garis sumbu Y. Oleh karena itu tidak terjadi gejala heteroskesdastisitas diregresi ini.

Karena hasil uji normalitas data menunjukkan data berdistribusi normal, diantara variabel bebas tidak ditemukan gejala multikolinearitas, dan model regresi yang dipakai tidak terdapat adanya heteroskedastisitas, maka analisis regresi linier berganda dapat lakukan proses selanjutnya.

Model Summary ${ }^{\mathrm{b}}$

\begin{tabular}{|c|c|c|c|c|c|c|c|c|c|}
\hline \multirow[b]{3}{*}{ Model } & \multirow[b]{3}{*}{$\mathrm{R}$} & \multirow[b]{2}{*}{$\mathrm{R}$} & \multirow[b]{2}{*}{ Adjusted } & \multirow{2}{*}{$\begin{array}{l}\text { Std. Error } \\
\text { of the }\end{array}$} & \multicolumn{5}{|c|}{ Change Statistics } \\
\hline & & & & & R Square & $\mathrm{F}$ & & & Sig. F \\
\hline & & Square & R Square & Estimate & Change & Change & df1 & df2 & Change \\
\hline 1 & $.804^{a}$ & .647 & .638 & .841825 & .647 & 70.583 & 2 & 77 & .000 \\
\hline
\end{tabular}

a. Predictors: (Constant), X2, X1

b. Dependent Variable: $Y$

Berdasarkan persamaan garis regresi tersebut, didapatkan interpretasi hasilnya sebagai berikut. Pertama, konstanta 2,051 menunjukkan jika variabel harapan pelanggan $\left(X_{1}\right)$ dan kualitas pelayanan $\left(\mathrm{X}_{2}\right)$ bernilai konstan, oleh karena itu variabel kepuasan pelanggan $(\mathrm{Y})$ bernilai 2,051 satuan. Kedua, harapan pelanggan $\left(X_{1}\right)$ memiliki koefisien regresi $\left(\beta_{1}\right)$ sebesar 0,328 . Nilai koefisien regresi positif memperlihatkan bahwa harapan pelanggan $\left(X_{1}\right)$ ada pengaruh positif terhadap kepuasan pelanggan $(Y)$. Hal ini tergambar bahwa setiap kenaikan 1 satuan harapan pelanggan $\left(X_{1}\right)$ dapat meningkatkan kepuasan pelanggan $(Y)$ sejumlah 0,328 dengan asumsi variabel independen lainnya posisi tetap. Ketiga, kualitas layanan $\left(\mathrm{X}_{2}\right)$ memiliki koefisien regresi $\left(\beta_{2}\right)$ sebesar 0,238 . Nilai koefisien regresi yang positif menunjukkan bahwa kualitas pelayanan $\left(\mathrm{X}_{2}\right)$ berpengaruh positif terhadap kepuasan pelanggan $(\mathrm{Y})$. Hal ini 
menggambarkan bahwa setiap kenaikan 1 satuan kualitas pelayanan $\left(X_{2}\right)$ dapat meningkatkan kepuasan pelanggan $(\mathrm{Y})$ sebesar 0,238 dengan asumsi variabel independen yang lainnya tetap

\begin{tabular}{llrrrrr}
\multicolumn{7}{c}{ ANOVA $^{\mathrm{a}}$} \\
\hline Model & Sum of Squares & df & Mean Square & \multicolumn{1}{c}{ F } & Sig. \\
\hline 1 & Regression & 100.041 & 2 & 50.020 & 70.583 & $.000^{\mathrm{b}}$ \\
& Residual & 54.568 & 77 & .709 & & \\
& Total & 154.608 & 79 & & & \\
\hline
\end{tabular}

a. Dependent Variable: $Y$

b. Predictors: (Constant), X2, X1

Data hasil penelitian menggambarkan bahwa harapan konsumen dan kualitas pelayanan secara simultan berpengaruh secara positif terhadap kepuasan konsumen dari PDAM Buleleng. Hal itu diperjelas dengan $p$-value Ryx $_{1} x_{2}=0,000<\alpha=0,05$. Besar sumbangan pengaruh secara bersama dari harapan pelanggan dan kualitas pelayanan terhadap kepuasan pelanggan adalah 0,647 . Hasil uji tersebut menggambarkan bahwa sebesar $64,7 \%$ kepuasan pelanggan dipengaruhi oleh variabel harapan pelanggan dan kualitas pelayanan, sedangkan pengaruh dari variabel lain sebesar $35,3 \%$.

Coefficients $^{\mathrm{a}}$

\begin{tabular}{|c|c|c|c|c|c|c|c|c|c|}
\hline \multirow{2}{*}{\multicolumn{2}{|c|}{ Model }} & \multicolumn{2}{|c|}{$\begin{array}{c}\text { Unstandardized } \\
\text { Coefficients }\end{array}$} & \multirow{2}{*}{$\begin{array}{c}\text { Standardized } \\
\text { Coefficients }\end{array}$} & \multirow{3}{*}{$\begin{array}{c}t \\
3.938\end{array}$} & \multirow{3}{*}{$\begin{array}{l}\text { Sig. } \\
.000\end{array}$} & \multicolumn{3}{|c|}{ Correlations } \\
\hline & & $B$ & Std. Error & & & & Zero-order & Partial & Part \\
\hline \multirow[t]{3}{*}{1} & (Constant) & 2.051 & .521 & & & & & & \\
\hline & $\mathrm{X} 1$ & .328 & .067 & .427 & 4.862 & .000 & .721 & 485 & .329 \\
\hline & $x 2$ & .238 & .045 & .463 & 5.275 & .000 & .734 & .515 & .357 \\
\hline
\end{tabular}

a. Dependent Variable: $Y$

Data hasil penelitian juga menunjukkan bahwa ada efek atau pengaruh harapan pelanggan terhadap kepuasan pelanggan. kekuatan hubungan efek dari harapan pelanggan terhadap kepuasan pelanggan sejumlah 0,485 dan besar sumbangan itu pengaruh adalah $23,5 \%$ dengan $p$-value $\mathrm{Pyx}_{1}=0,000<\alpha=0,05$. Hal ini menunjukan bahwa harapan pelanggan ada pengaruh secara positif kepada kepuasan pelanggan. Artinya, jika harapan pelanggan tinggi, maka kepuasan pelanggan juga akan semakin tinggi. Data hasil penelitian juga menunjukkan bahwa ada pengaruh dari kualitas pelayanan terhadap kepuasan pelanggan. Keeratan hubungan pengaruh kualitas pelayanan terhadap kepuasan pelanggan sebesar 0,515 dan besar sumbangan pengaruh dari kualitas pelayanan terhadap kepuasan pelanggan adalah 26,5\% dengan $p$-value $\mathrm{Pyx}_{2}=0,000<\alpha=0,05$. Hal ini menunjukan bahwa kualitas pelayanan berpengaruh secara positif terhadap kepuasan pelanggan. Artinya jika kualitas pelayanan semakin baik, maka kepuasan pelanggan juga akan semakin tinggi.

Berdasarkan riset yang telah dilaksanakan bahwa variabel harapan pelanggan dan kualitas pelayanan ada pengaruh signifikan terhadap kepuasan pelanggan pada PDAM Kabupaten Buleleng. Hasil riset ini dapat mendukung sebuah teori yang disampaikan oleh Kotler (2005) bahwa jika hasil kerja berada di bawah harapan maka pelanggan tidak puas. Jika hasil kerja memenuhi harapan maka pelanggan puas. Jika hasil kerja melebihi harapan maka pelanggan amat puas atau senang. Pengaruh antara harapan pelanggan dan kualitas pelayanan terhadap kepuasan konsumen dikuatkan dengan jurnal dalam penelitian yang dilaksanakan Michele (2011) yang menunjukkan kualitas pelayanan dan harapan pelanggan ada pengaruh positif dan signifikan terhadap kepuasan pelanggan serta kepuasan pelanggan 
dapat meningkat bila kualitas layanan dan harapan pelanggan secara simultan terpenuhi. Kajian emperik yang ikut serta mendukung temuan penelitian adalah hasil penelitian yang dilaksanakan oleh Sanjaya (2011), yang ditemukan bahwa kualitas produk dan harapan pelanggan ada pengaruh positif dan signifikan terhadap puasnya pelanggan.

Penelitian tentang pengaruh dari variabel harapan pelanggan terhadap kepuasan pelanggan, diperoleh hasil variabel harapan pelanggan berpengaruh positif terhadap kepuasan pelanggan pada PDAM Kabupaten Buleleng. Temuan ini didukung oleh teori dari Zairi (2000) dalam Khan (2012) bahwa yang diharapkan pelanggan dalam perihal kualitas dan layanan akan ditimbulkan kepuasan pelanggan. Bila kepuasan pelanggan mampu berkembang, konsumen akan menjadi lebih loyal terhadap suatu nama produk ataupun jasa tersebut. Pelanggan yang berharap tinggi, akan cenderung sulit untuk puas, atau mendapatkan kepuasan. Sedangkan pelanggan yang memiliki harapan rendah untuk sesuatu pelayanan, akan mudah untuk puas atau dengan mudah mendapatkan kepuasan pelanggan. Kajian emperik yang turut mendukung penelitian ini adalah hasil penelitian yang dilaksanakan oleh Trijayanti (2016), yang ditemukan bahwa ada pengaruh positif antara harapan pelanggan terhadap puas pelanggan.

Hasil lanjutan penelitian yang diperoleh adalah variabel kualitas pelayanan ada pengaruh positif terhadap kepuasan pelanggan pada PDAM Buleleng. Hasil penelitian sesuai dengan Juran (1998) yang membuat suatu pernyataan bahwa pelanggan dapat dilihat puas bila kualitas pelayanan yang telah dilaksanakan dapat memenuhi keperluan dan kebutuhan pelanggan. Kualitas pelayanan baik memungkinkan perusahaan untuk meningkatkan kepuasan dan mengurangi ketidakpuasan dari pelanggan. Semakin baik kualitas pelayanan akan dapat dikurangi kerja ulang dan pada akhirnya angka ketidakpuasan pelanggan dapat diturunkan. Kajian empirik yang ikut serta mendukung temuan dari penelitian adalah hasil penelitian yang telah dilakukan oleh Ulum (2013), yang menyebutkan bahwa kualitas pelayanan ada pengaruh positif dan signifikan terhadap kepuasan pelanggan.

\section{Simpulan dan Saran}

Atas dasar hasil uji statistik dan hipotesa serta pembahasan yang telah dilaksanakan, dapat diambil simpulan sebagai berikut. Pertama, harapan pelanggan ada pengaruh positif dan signifikan terhadap kepuasan pelanggan atau konsumen pada PDAM Kabupaten Buleleng. Artinya, jika semakin tinggi harapan pelanggan, maka kepuasan pelanggan pada PDAM Kabupaten Buleleng semakin tinggi. Kedua, kualitas layanan ada pengaruh positif dan signifikan terhadap kepuasan pelanggan di PDAM Buleleng. Dapat diartikan, jika semakin baik kualitas pelayanan, maka kepuasan pelanggan pada PDAM Kabupaten Buleleng semakin tinggi. Ketiga, harapan pelanggan dan kualitas layanan berpengaruh positif dan signifikan terhadap kepuasan pelanggan pada PDAM Buleleng. Artinya, jika semakin baik harapan pelanggan dan semakin baik kualitas layanan, maka kepuasan pelanggan pada PDAM Buleleng semakin tinggi.

Saran yang dapat diberikan atas dasar penelitian ini adalah sebagai berikut. Pertama, bagi pihak perusahaan PDAM Kabupaten Buleleng, agar lebih memperhatikan harapan pelanggan dan kualitas pelayanan dalam upaya peningkatan kepuasan pelanggan, karena penelitian ini membuktikan bahwa harapan pelanggan dan kualitas pelayanan dapat mempengaruhi kepuasan pelanggan. Hal tersebut karena harapan pelanggan dan kualitas pelayanan bertujuan untuk meningkatkan kepercayaan, sehingga akan mendukung terciptanya kepuasan pelanggan yang meningkat. Kedua, bagi peneliti selanjutnya yang ingin untuk mengkaji aspek yang sama yaitu harapan pelanggan, kualitas pelayanan, dan kepuasan pelanggan diharapkan untuk dapat melakuakn pengembangan penelitian ini dengan populasi dan sampel yang lebih luas agar hasil penelitian semakin teruji keandalannya. Selain itu, diharapkan untuk menguji lebih lanjuy variabel lain yang diduga ada pengaruh kuatyang dapat mempengaruhi kepuasan pelanggan. 


\section{Daftar Pustaka}

Abdullatif. 2016. Pengaruh Harapan Pelanggan, Nilai Pelanggan, dan Kualitas Pelayanan Terhadap Kepuasan Pelanggan Pada Pengguna Jasa Kereta Commuterline Jabodetabek. Skripsi. Jurusan Manajemen, Fakultas Ekonomi dan Bisnis, UIN Syarif Hidayatullah Jakarta.

Hays, W. L. 1969. Statistics. London: Holt, Rinehart \& Winston.

Juran, Joseph M. 1998. Juran’s Quality Handbook. New York: McGrawHill.

Kotler, Philip. 2005. Manajemen Pemasaran. Jakarta: Indeks Kelompok Gramedia.

Mushtaq, Irfan and Khan, S. N. 2012. Factor Affecting Students' Academic Performance. Global Journal of Management and Business Research, Vol. 12, No. 9, Hal: 2249-4588.

Oliver, Richard. 1993. A Conceptual Model of Service Quality and Service Satisfaction; Compatible Goal, Different Concept. Advances in Services Marketing and Management: Research and Practice, Vol 2, Hal: 65-85.

Pratiwi, Dinar Ika. 2010. Analisis Pengaruh Harapan Pelanggan, Kualitas Produk, Kepuasan Pelanggan Terhadap Loyalitas Pelanggan Internet Flash Unlimited di Semarang. Skripsi. Semarang: Universitas Diponegoro.

Sanjaya, Michele Marcia O’Keefee Marta. 2011. Pengaruh Kualitas Produk dan Harapan Pelanggan Terhadap Tingkat Kepuasan Pelanggan PT. Telekomunikasi Seluler Pengguna Bundling Telkomsel Dengan Iphone 4. Tesis. Jurusan Komunikasi Pemasaran, Bina Nusantara Jakarta.

Tjiptono, Fandy dan Chandra, Gregorious. 2011. Service, Quality and Satisfaction. Yogyakarta: Andi.

Trijayanti, Rina Apri.2016. Pengaruh Merek, Persepsi Harga dan Harapan Pelanggan Terhadap Kepuasan Konsumen Kentucky Fried Chicken (KFC) (Studi pada Mahasiswa UNY). Skripsi. Jurusan Manajemen, Universitas Negeri Yogyakarta.

Ulum, lqbal Miftakhul. 2013. Analisis Pengaruh Harapan Pelanggan dan Kualitas Pelayanan Terhadap Kepuasan dan Loyalitas Pelanggan Jasa Transportasi Kereta Api Logawa Pada PT Kereta Api Indonesia DAOP IX Jember. Skripsi. Fakultas Ekonomi, Universitas Jember.

Widodo, Joko. 2009. Analisis Kebijakan Publik Konsep dan Aplikasi Analisis Proses Kebijakan Publik. Malang: Bayumedia Publishing.

Wilkie, W. L. 1990. Consumer Behavior. New York: John Wiley \& Sons. 